\section{Release of Cornell 601-606: Common Bean Breeding Lines with Resistance to White Mold}

\author{
Phillip D. Griffiths ${ }^{1}$ \\ Hedrick Hall, Geneva, NY 14456 \\ Additional index words. Phaseolus vulgaris L., Sclerotinia sclerotiorum
}

Department of Horticultural Sciences, Cornell University NYSAES, 315

The New York State Agricultural Experiment Station announces the release of six dry bean (Phaseolus vulgaris L.) breeding lines with resistance to white mold [Sclerotinia sclerotiorum (Lib.) de Bary]. These breeding lines, Cornell 601 (pink kidney), Cornell 602 (white kidney), Cornell 603 (dark red kidney), Cornell 604 (black bean), Cornell 605 (light red kidney), and Cornell 606 (black kidney), represent germplasm with high levels of resistance to white mold developed through greenhouse selection and evaluation in multistate greenhouse and field comparisons through the w-1150 regional project.

White mold is a serious disease of common bean worldwide reducing both yield and quality (Kerr et al., 1978). Host plant resistance can be conferred through both plant architecture and physiological resistance (Kolkman and Kelly, 2003). White mold resistance can be selected through a technique known as the "straw test," which shows a very high correlation with field resistance (Petzoldt and Dickson, 1996). This test was used to develop the six breeding lines by modification of the straw test to inoculate two plant petioles (Griffiths et al., 2004).

\section{Origin and Description}

Lines Cornell 601, Cornell 602, Cornell 603, Cornell 604, Cornell 605, and Cornell 606 were selected after an initial cross between red kidney bean cultivar Redkote (Cornell University, Geneva, NY) and Cornell snap bean breeding line 6603. Line 6603 was developed from a cross between snap bean breeding lines 5223 and 5813, the pedigrees of which were described previ-

Received for publication 18 Sept. 2008. Accepted for publication 30 Nov. 2008.

I thank Helene Dillard for the pathogen isolate used in this work, Jim Steadman and Lindsey Otto-Hansen for coordinating w-1150 multistate white mold trials, and the Cornell Vegetable Breeding Institue and the New York Dry Bean Advisory Board for helping support this work. This research is a contribution to the objectives of the w-1150 regional project.

${ }^{1}$ To whom reprint requests should be addressed; e-mail pdg8@cornell.edu. ously (Griffiths et al., 2004). Lines Cornell 601 and Cornell 602 were selected as $F_{10}$ lines from the initial cross followed by repeated selection of the progeny using the straw test procedure at the $\mathrm{F}_{3}-\mathrm{F}_{9}$ generations (Fig. 1). Breeding line Cornell 601 was crossed with light red kidney cultivar RedKanner (Cornell University, Geneva, NY), dark red kidney cultivar Montcalm (Michigan State University, East Lansing, MI), and black bean cultivar T-39 (University of California Davis, Davis, CA). Populations developed from these crosses were used to select resistance to white mold in multiple market classes through repeated greenhouse selections with single plant recurrent selection of breeding lines (Fig. 1).

The six dry bean (Phaseolus vulgaris L.) breeding lines being released differ in market class and seed type; Cornell 601 is a small pink kidney bean, Cornell 602 is a small white kidney bean, Cornell 603 is a small dark red kidney bean, Cornell 604 is a black bean, Cornell 605 is a light red kidney bean, and Cornell 606 is a large black bean with kidney bean plant characteristics (Fig. 2A-B). The black bean lines Cornell 604 and 606 have a mean seed weight at $12 \%$ moisture of $0.258 \mathrm{~g}$ and $0.321 \mathrm{~g}$, respectively, which is larger than commercial black bean varieties. The breeding lines have been evaluated for white mold resistance in multistate greenhouse and field trials as part of the $\mathrm{w}-1150$ multistate regional project between 2004 and 2007 (Tables 1 and 2).

Greenhouse inoculations for the development of the breeding lines were performed at NY with 2- to 3-d-old actively growing mycelia of white mold isolate \#48 collected from a snap bean field in Murray, Orleans County, NY (Helene Dillard, NYSAES, Cornell Univ., Geneva, NY) grown on $2 \%$ potato dextrose agar (Difco, Sparks, MD). Plants were grown in $15-\mathrm{cm}$ diameter square pots in Cornell mix (Boodley and Sheldrake, 1982) in greenhouses at $25 / 22{ }^{\circ} \mathrm{C}$ day/night with a 14-h photoperiod under $1000-\mathrm{W}$ metal halide lamps $\left(300 \mu \mathrm{mol} \cdot \mathrm{m}^{-2} \cdot \mathrm{s}^{-1}\right)$ in preparation for the inoculation. Plants were inoculated using a modified technique that involved double inoculation of each plant with two $3-\mathrm{cm}$ straws placed on petioles cut $5 \mathrm{~cm}$ from the nodes 24 to $28 \mathrm{~d}$ after planting. Plants were evaluated for disease severity $14 \mathrm{~d}$ after inoculation, and selections of resistant plants were made based on aggressiveness and severity of the white mold growth. Ratings were made based on a 1 to 5 scale, in which $1=$ no progression of symptoms beyond the first node, 2 = some progression of symptoms

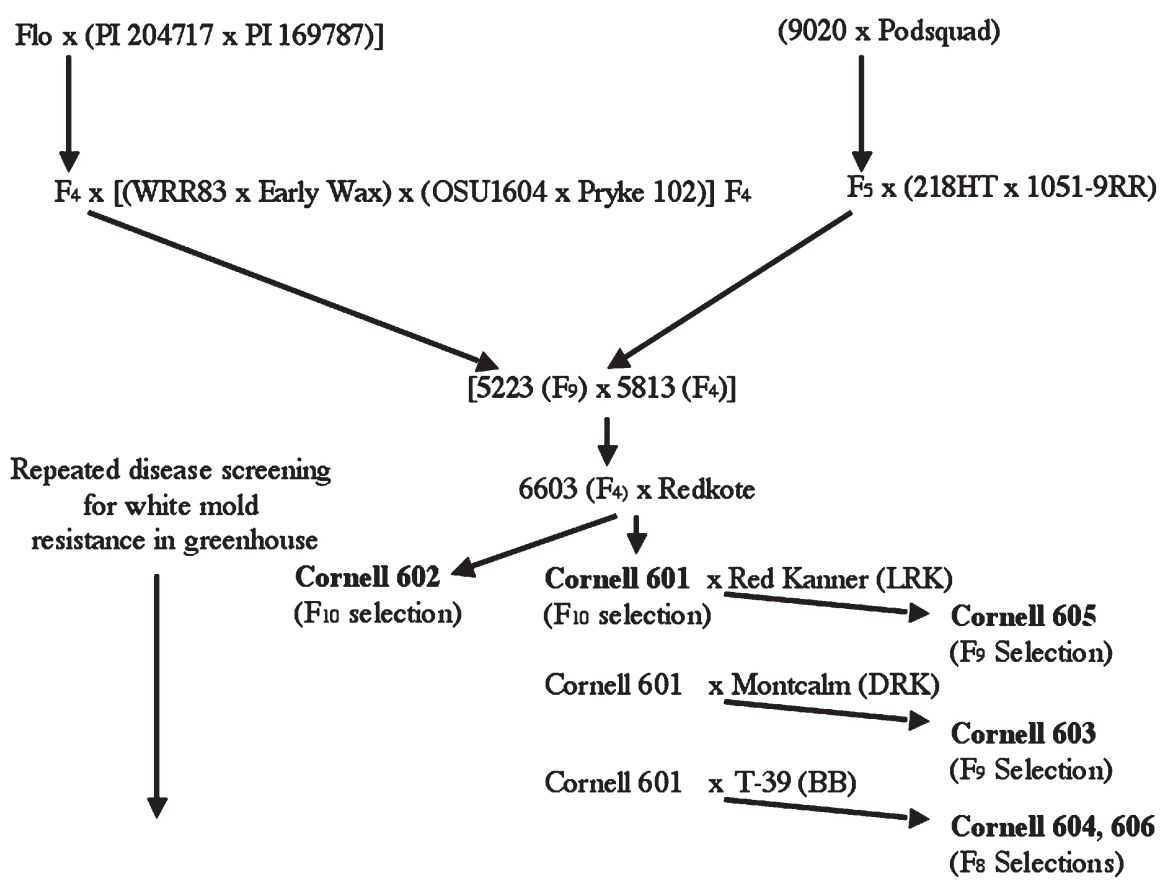

Fig. 1. Pedigree of white mold-resistant breeding lines Cornell 601, Cornell 602, Cornell 603, Cornell 604, Cornell 605, and Cornell 606. LRK, light red kidney; DRK, dark red kidney; BB, black bean. 
A

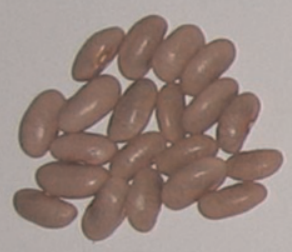

Cornell 601

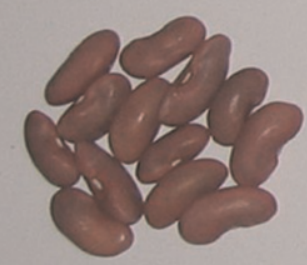

CELRK
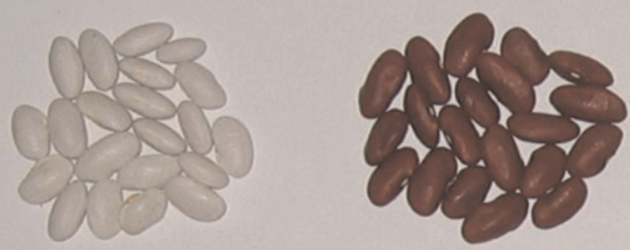

Cornell 602

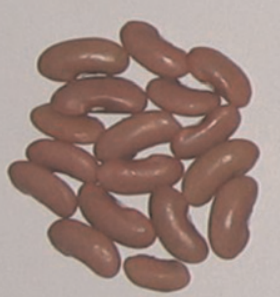

1060-V98
Cornell 603

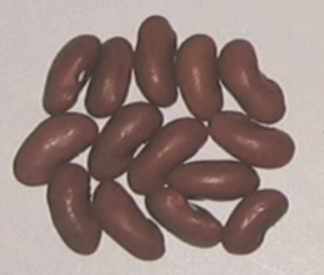

Montcalm

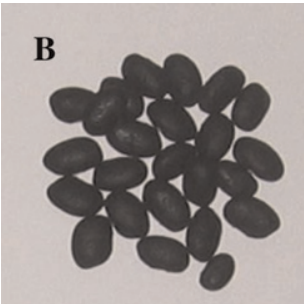

Cornell 604

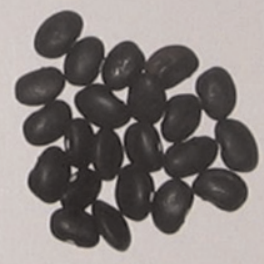

Mill. Black

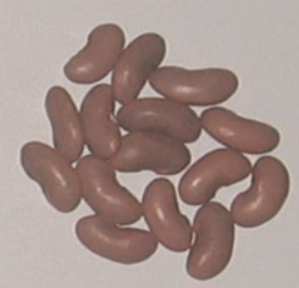

Cornell 605

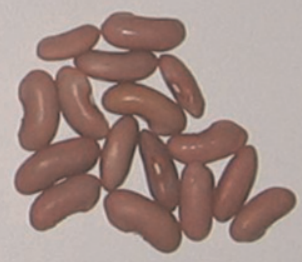

Red Kanner

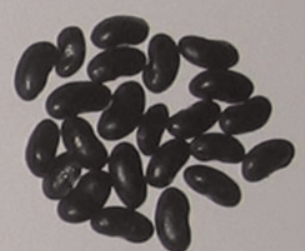

Cornell 606

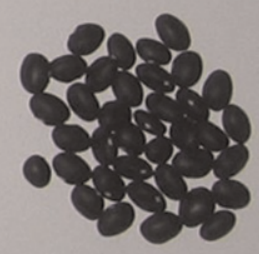

T-39

Fig. 2. (A-B) Dry seed of Cornell 601, Cornell 602, Cornell 603, Cornell 604, Cornell 605, and Cornell 606 relative to commercial cultivars and breeding lines in similar market classes of common bean.

Table 1. Mean rankings of Cornell 601, Cornell 602, Cornell 603, Cornell 604, Cornell 605, and Cornell 606 in w-1150 multistate greenhouse trials compared with the resistant chack G-122 and the susceptible control Beryl. ${ }^{2}$

\begin{tabular}{lcccc}
\hline Genotype & 2004 rank & 2005 rank & 2006 rank & 2007 rank \\
\hline Cornell 601 & 2 & 5 & - & - \\
Cornell 602 & - & - & - & - \\
Cornell 603 & - & 1 & 2 & 9 \\
Cornell 604 & - & - & 9 & 4 \\
Cornell 605 & - & 3 & 8 & 3 \\
Cornell 606 & 3 & 13 & 7 & 6 \\
G-122 & 13 & 14 & 17 & 7 \\
Beryl & 9 & 13 & 8 & 17 \\
No. multistate tests & 13 & 22 & 7 \\
Total entries &
\end{tabular}

${ }^{\mathrm{z} O t t o-H a n s e n ~ a n d ~ S t e a d m a n, ~ 2008 ; ~ S t e a d m a n ~ a n d ~ O t t o-H a n s e n, ~ 2005, ~ 2006, ~} 2007$.

beyond the first node, $3=$ progression of symptoms to the second node, $4=$ progression of symptoms beyond the second node, and $5=$ complete susceptibility and death of the plant.

Five of the six breeding lines have been evaluated in multistate greenhouse and field trials for white mold resistance between 2004 and 2007 as part of the w-1150 regional project (Tables 1 and 2). In 2004, Cornell 601 ranked second of 13 entries in field and greenhouse trials for resistance to white mold (Steadman and Otto-Hansen, 2005). In 2005, Cornell 601, Cornell 604, and Cornell 606 ranked fifth, first, and third, respectively, of 12 entries in greenhouse tests, and sixth, fourth, and third, respectively, in multistate field tests (Steadman and Otto-Hansen, 2006). In 2006, Cornell 603, Cornell 604, Cornell 605, and Cornell 606 ranked second, ninth, first, and eighth, respectively, in greenhouse trials among 22 entries, and eighth, second, first, and third, respectively, among 13 entries in multistate field trials (Steadman and Otto-Hansen, 2007); additionally, Cornell 601 was field tested in 2006, in which it ranked fourth among the 13 entries. In 2007, Cornell 604, Cornell 605, and Cornell 606 ranked ninth, fourth, and third, respectively, among 17 entries in greenhouse testing, and third, sixth, and second, respectively, among 12 entries in multistate field testing (OttoHansen and Steadman, 2008). The w-1150 field evaluations were not necessarily a measure of physiological resistance, because the plant canopy can affect the growth and development of the disease by altering the microclimate.

Cornell 601 yielded $2946 \mathrm{lb} / \mathrm{acre}$ at 18\% moisture in 2005 yield trials in Tompkins County, NY, with $97 \mathrm{~d}$ to maturity at the $90 \%$ dry pod stage compared with California Early Light Red Kidney (University of California Davis, Davis, CA), which yielded $3073 \mathrm{lb} /$ acre with $92 \mathrm{~d}$ to maturity. Cornell 603 yielded $2362 \mathrm{lb} /$ acre in 2008 field trials in Wayne County, NY, and $2172 \mathrm{lb} / \mathrm{acre}$ in Tompkins County, NY, with a $90 \%$ pod maturity of 94 d compared with Montcalm, which yielded $1889 \mathrm{lb} /$ acre and $2790 \mathrm{lb} / \mathrm{acre}$, respectively, with $100 \mathrm{~d}$ to maturity. Cornell 604 yielded $1500 \mathrm{lb} /$ acre in 2007 trials in Tompkins County, NY, with $102 \mathrm{~d}$ to maturity compared with T39, which yielded 2914 lb/acre with 103 d to maturity. Cornell 605 yielded $2589 \mathrm{lb} /$ acre in field trials in Wayne County, NY, with $95 \mathrm{~d}$ to maturity and 2865 lb/acre in Tompkins County, NY, with $99 \mathrm{~d}$ maturity compared with Redkanner, which yielded $2993 \mathrm{lb}$ /acre with $98 \mathrm{~d}$ to maturity and $2579 \mathrm{lb} /$ acre with $103 \mathrm{~d}$ to maturity, respectively (Halseth and Sandsted, data not shown). Field data for Cornell 602 and Cornell 606 are not available. The mean seed weights at $12 \%$ moisture content of Cornell $601,602,603,604,605$, and 606 were $0.31 \mathrm{~g}$, $0.32 \mathrm{~g}, 0.48 \mathrm{~g}, 0.26 \mathrm{~g}, 0.46 \mathrm{~g}$, and $0.32 \mathrm{~g}$, respectively. Table 3 represents the performance of the six breeding lines in 2005 greenhouse evaluations. The results represent the mean rating of 20 plants after greenhouse inocula- 
Table 2. Mean rankings of Cornell 601, Cornell 602, Cornell 603, Cornell 604, Cornell 605, and Cornell 606 in w-1150 multistate field trials compared with the resistant chack G-122 and the susceptible control Beryl.

\begin{tabular}{lcccc}
\hline Genotype & 2004 rank & 2005 rank & 2006 rank & 2007 rank \\
\hline Cornell 601 & 2 & 6 & 4 & - \\
Cornell 602 & - & - & - & - \\
Cornell 603 & - & - & 2 & 3 \\
Cornell 604 & - & - & 1 & 6 \\
Cornell 605 & - & 3 & 3 & 2 \\
Cornell 606 & 3 & 3 & 3 & 1 \\
G-122 & 13 & 13 & 22 & 13 \\
Beryl & 7 & 13 & 8 & 6 \\
No. multistate tests & 13 & 13 & 22 & 13 \\
Total entries & & - & 2 & \\
\hline
\end{tabular}

${ }^{\mathrm{z} O t t o-H a n s e n ~ a n d ~ S t e a d m a n, ~ 2008 ; ~ S t e a d m a n ~ a n d ~ O t t o-H a n s e n, ~ 2005, ~ 2006, ~} 2007$.

Table 3. Greenhouse evaluation of Cornell 601, $602,603,604,605$, and 606 in 2005 greenhouse trials at Cornell University, Geneva, NY. ${ }^{z}$

\begin{tabular}{llr}
\hline Genotype & \multicolumn{1}{c}{ Rating } & Rank \\
\hline Cornell 605 & $1.13 \mathrm{~A}^{\mathrm{y}}$ & 1 \\
Cornell 602 & $1.44 \mathrm{AB}$ & 2 \\
Cornell 603 & $1.56 \mathrm{AB}$ & 3 \\
Cornell 604 & $1.60 \mathrm{ABC}$ & 4 \\
Cornell 601 & $2.22 \mathrm{ABCDE}$ & 7 \\
Cornell 606 & $2.29 \mathrm{ABCDE}$ & 8 \\
G122 & $2.50 \mathrm{ABCDEF}$ & 8 \\
Dwarf Bees & $2.89 \mathrm{DEFGH}$ & 13 \\
Ex-Rico & $4.13 \mathrm{HIJK}$ & 21 \\
Beryl & $4.30 \mathrm{JK}$ & 23 \\
\hline
\end{tabular}

${ }^{\mathrm{z}}$ Table represents relative ranking and means grouping differences when compared with the resistant control G-122, intermediate control Dwarf Bees, and susceptible controls Ex-Rico and Beryl. Results based on data submitted to w1150 greenhouse trials (Steadman and OttoHansen, 2006).

${ }^{y}$ Means separation according to Duncan's multiple range test $(P \leq 0.05)$. tions. The evaluation was made based on the 1 to 5 rating scale previously described $14 \mathrm{~d}$ after inoculation. The resistant and susceptible controls from the w-1150 trials were included to highlight statistical differences between the breeding lines and susceptible controls after inoculation. The performance of the breeding lines in multistate field testing indicates that they have high levels of resistance to white mold that can be used as white mold-resistant germplasm resources for the development of commercial dry bean cultivars.

\section{Availability}

Small amounts of seed are available from P. D. Griffiths, New York State Agricultural Experiment Station, Cornell University, Department of Horticultural Sciences, 315 Hedrick Hall, Geneva, NY 14456 with a material transfer agreement.

\section{Literature Cited}

Boodley, J.W. and R. Sheldrake Jr. 1982. Cornell peat-lite mixes for commercial plant growing. New York Agr. Exp. Sta. Agr. Info. Bul. 43.

Griffiths, P.D., M.M. Jahn, and M.H. Dickson. 2004. Cornell 501: A white mold tolerant snap bean breeding line. HortScience 39:15071508.

Kerr, E.D., J.R. Steadman, and L.A. Nelson. 1978. Estimation of white mold disease reduction of yield and yield components of dry edible beans. Crop Sci. 18:275-279.

Kolkman, J.M. and J.D. Kelly. 2003. QTL conferring resistance and avoidance to white mold in common bean. Crop Sci. 43:539-548.

Petzoldt, R. and M.H. Dickson. 1996. Straw test for resistance to white mold in beans. Annu. Rpt. Bean Improv. Coop. 39:142-143.

Otto-Hansen, L.K. and J. Steadman. 2008. Use of multi-site screening to identify partial resistance to white mold in common bean in 2007 . Bean Improv. Coop. 51:214-215.

Steadman, J.R. and L.K. Otto-Hansen. 2005. Identification of partial resistance to Sclerotinia sclerotiorum in common bean at multiple locations. Annu. Rpt. Bean Improv. Coop. 48:124-125.

Steadman, J.R. and L.K. Otto-Hansen. 2006. Use of multi-sites to identify partial resistance to Sclerotinia sclerotorum in common bean over multiple years. Annu. Rpt. Bean Improv. Coop. 49:91-92.

Steadman, J.R. and L.K. Otto-Hansen. 2007. Identification of partial resistance to Sclerotinia sclerotiorum in common bean at multiple locations in 2006. Annu. Rpt. Bean Improv. Coop. 50:133-134. 